Jurnal Media Pertanian Vol. 2 No. 2 Tahun 2017 Hal. 47 - 54

Media Komunikasi Hasil Penelitian dan Review Literatur Bidang Ilmu Agronomi

ISSN print $2503-1279$

ISSN online $2581-1606$

\title{
TANGGAP BIBIT KAKAO TERHADAP MEDIA TANAM GAMBUT DAN ULTISOL SERTA ZEOLIT
}

\author{
Ida Nursanti \\ Program Studi Agroteknologi, Fakultas Pertanian Universitas Batanghari \\ Jl. Slamet Riyadi, Broni Jambi, 36122. Telp. +6274160103 \\ email : ida_unbari@yahoo.co.id
}

\begin{abstract}
Peat soils and mineral soils have poor chemical and biological properties. The addition of mineral soil and zeolite in peat plant media will improve the soil properties. The aim of this research is to know the effect of ultisol and zeolite soil on peat media and to determine the ratio of ultisol and peat soil media and zeolite for the growth of cocoa seedlings. Implementation of research in Jambi City. The study used Completely Randomized Design (RAL) with 2 factors. Giving ultisol soil $(U)$ with 4 levels : UO = without ultisol soil, $U 1=$ ultisol soil $15 \%$ by weight of planting medium, $U 2=$ ultisol soil $20 \%$ by weight of planting medium, U3 = ultisol soil $25 \%$ weight of planting medium. Zeolite $(\mathrm{Z})$ with 3 levels ie: $\mathrm{ZO}=$ zeolite, $\mathrm{Z1}=$ zeolite $100 \mathrm{~g}$ and $\mathrm{Z2}=$ zeolite 200g. Observation of: height of plant (cm), dry weight of crown ( $\mathrm{g}$ ), leaf $N$ content (\%), and leaf P content (\%). The observed data were analyzed using Duncan Multiple Range Test (DNMRT) and Duncan Multiple Range Test (DNMRT) test at 5\% level. The administration of ultisol and zeolite soils on peat moss can significantly influence the growth of cocoa seeds, especially in plant height, dry crown weight, leaf $N$ content and leaf $P$ content. Ultisol soil $25 \%$ and zeolite $200 \mathrm{~g}$ on peat media can better influence the growth of cocoa seedlings.
\end{abstract}

Keywords : Peat, Ultisol, Zeolit, Cocoa

\begin{abstract}
Abstrak
Tanah gambut dan tanah mineral memiliki sifat kimia dan biologi kurang baik. Penambahan tanah ultisol dan zeolit dalam media tanam gambut akan dapat memperbaiki sifat tanah. Penelitian bertujuan mengetahui pengaruh pemberian tanah ultisol dan zeolit pada media gambut serta menentukan perbandingan media tanah ultisol, zeolit dan gambut untuk pertumbuhan bibit kakao. Pelaksanaan penelitian di Kota Jambi. Penelitian menggunakan Rancangan Acak Lengkap (RAL) dengan 2 faktor. Pemberian tanah ultisol (U) dengan 4 taraf yaitu :U0 $=$ tanpa pemberian tanah ultisol, $\mathrm{U} 1=$ tanah ultisol $15 \%$ berat medium tanam, U2=tanah ultisol $20 \%$ berat medium tanam, U3=tanah ultisol $25 \%$ berat medium tanam. Zeolit (Z) dengan 3 taraf yaitu $: Z 0=$ tanpa zeolit, $\mathrm{Z1}=$ zeolit $100 \mathrm{~g}$ dan $\mathrm{Z} 2=$ zeolit 200g. Pengamatan terhadap: tinggi tanaman $(\mathrm{cm})$, bobot kering tajuk $(\mathrm{g})$, kadar $\mathrm{N}$ daun $(\%)$, dan kadar $\mathrm{P}$ daun (\%). Data hasil pengamatan dianalisa menggunakan analisis ragam dan uji Duncan New Multiple Range Test (DNMRT) pada taraf 5\%. Pemberian tanah ultisol dan zeolit pada media gambut dapat mempengaruhi pertumbuhan bibit kakao secara signifikan terutama pada tinggi tanaman, bobot kering tajuk, kadar $\mathrm{N}$ daun dan kadar $\mathrm{P}$ daun. Tanah ultisol $25 \%$ dan zeolit $200 \mathrm{~g}$ pada media gambut dapat lebih baik mempengaruhi pertumbuhan bibit kakao.
\end{abstract}

Kata kunci : Gambut,Ultisol, Zeolit, Kakao 
Jurnal Media Pertanian Vol. 2 No. 2 Tahun 2017 Hal. 47 - 54

Media Komunikasi Hasil Penelitian dan Review Literatur Bidang Ilmu Agronomi

ISSN print $2503-1279$ ISSN online $2581-1606$

\section{PENDAHULUAN}

Salah satu aspek yang perlu mendapat perhatian didalam menunjang program pengembangan pertanaman kakao adalah penyediaan bibit yang sehat, potensinya unggul dan tepat pada waktunya. Untuk mendapatkan bibit yang baik perlu diciptakan kondisi yang mendukung pertumbuhannya, seperti kebutuhan akan unsur-unsur hara, baik unsur hara makro maupun unsur hara mikro (Lubis, 2012). Untuk mendukung pengembangan tanaman kakao agar berhasil dengan baik, langkah awal usaha budidaya kakao yang baik adalah mempersiapkan bahan tanam di tempat pembibitan. Karena pembibitan merupakan pertumbuhan awal suatu tanaman sebagai penentu pertumbuhan selanjutnya maka pemeliharaan dalam pembibitan harus lebih intensif dan diperhatikan. Selain pemupukan, pertumbuhan bibit kakao juga dipengaruhi jenis tanah yang digunakan sebagai media.

Sejalan dengan peningkatan jumlah penduduk dan permintaan terhadap produk pertanian maka kebutuhan akan perluasan lahan pertanian juga meningkat. Lahan yang dulunya dianggap sebagai lahan marjinal, seperti lahan gambut, menjadi salah satu sasaran perluasan lahan pertanian. Lahan gambut di Provinsi Jambi arealnya cukup luas, yaitu sekitar 621.086 ha yang mempunyai potensi untuk dijadikan untuk lahan pertanian (BB Litbang SDLP, 2011).

Tanah gambut memiliki berat isi atau buld density (BD) lapisan atas sangat rendah antara 0,1 sampai $0,2 \mathrm{~g} / \mathrm{cm}^{3}$. menyebabkan daya menahan atau menyangga beban (bearing capacity) menjadi sangat rendah. Gambut bersifat mengering tidak balik, gambut yang telah mengering tidak bisa menyerap air lagi kalau dibasahi. Gambut memiliki pH 3-5, sebagian besar kation basa terkandung sangat rendah dan kation asam sangat tinggi, C-Organik sangat tinggi serta kadar unsur hara yang sangat rendah (Agus dan Subiksa, 2008).

Tanah mineral di Indonesia umumnya juga memiliki sifat kimia yang kurang baik, dimana KTK, bahan organik tanah, stabilitas agregat tanah, kandungan unsur hara $\mathrm{N}, \mathrm{P}$, dan $\mathrm{K}, \mathrm{pH}$ tanah yang rendah, kejenuhan Al tinggi disamping itu, tetapi memiliki stabilitas agregat tanah yang lebih baik dibandingkan tanah gambut (Hardjowigeno, 2003).

Penambahan tanah mineral dalam media tanam gambut akan dapat mengurangi asam-asam organik yang dihasilkan selama proses dekomposisi yang bersifat racun bagi tanaman, yang dapat menghambat metabolisme tanaman danberakibat terhadap penurunan pertumbuhan dan produktifitasnya, karena tanah mineral memiliki tingkat kemasaman yang lebih rendah dibandingkan tanah gambut dan kaya akan bahan polivenol. Selain itu tanah mineral juga mengandung kation polivalen seperti $\mathrm{Fe}, \mathrm{Al}, \mathrm{Cu}$ dan Zn. Kation-kation tersebut membentuk ikatan koordinasi dengan ligan organik membentuk senyawa komplek/khelat. Oleh karenanya bahan-bahan yang mengandung kation polivalen tersebut bisa dimanfaatkan sebagai bahan amelioran gambut (Sibagaring, Wawan dan Yetti, 2013). Selanjutnya dijelaskan juga untuk memperoleh pertumbuhan tanaman padi yang baik dan dapat memberikan perbaikan sifat media tanam tanah gambut disarankan pemberian $21 \%$ tanah mineral dari berat media tanam dan diikuti dengan pemberian aerasi.

Sehubungan dengan hal di atas perlu dicobakan juga teknologi yang ramah lingkungan, seperti pemakaian Zeolit (Rahmawati, 2006). Manfaat Zeolit pada tanah dapat membenahi kondisi tanah (fisik, kimia dan biologi tanah), meningkatkan hara tanaman dan kapasitas tukar kation (KTK), mempengaruhi sifat kimia tanah seperti 
Jurnal Media Pertanian Vol. 2 No. 2 Tahun 2017 Hal. 47 - 54

Media Komunikasi Hasil Penelitian dan Review Literatur Bidang Ilmu Agronomi

ISSN print $2503-1279$

ISSN online $2581-1606$

peningkatan kalsium (Ca), kalium (K). Manfaat bagi tanaman dapat meningkatkan produktivitas dan kualitas produk, mempercepat pertumbuhan tanaman, meningkatkan ketahanan tanaman dari hama penyakit, mengefisienkan penggunaan pupuk (Al-Jabri, 2008).

Sebagai bahan pembenah tanah, jumlah zeolit yang perlu diberikan sekitar 10-20 ton/ha. Zeolit sebagai bahan pembenah tanah dapat meningkatkan KTK tanah yang dalam jangka panjang dapat mempertahankan kualitas tanah. (Suwardi, 2002). Secara kimia kandungan Zeolit yang utama Si02 62,75\%; A1203 12,71\%; K20 1,28\%; CaO 3,39\%; Na20 1,29\%; Mn0 5,58\%; Fe203 2,01\%; MgO 0,85\%; Clinoptilotin 30\%; Moedernit 49\%. Sedangkan nilai KTK antara 80-120 me/100 g, nilai yang tergolong tinggi untuk penilaian tingkat kesuburan tanah. Penelitian Rahmawati (2006) menyatakan bahwa perlakuan zeolit memberikan pengaruh nyata terhadap kadar air kapasitas lapang, $\mathrm{P}$ tersedia, serapan $\mathrm{P}$, berat kering tanaman dan tinggi tanaman.

\section{METODE PENELITIAN}

Penelitian dilaksanakan di kelurahan Paal Merah, Kecamatan Jambi Selatan, Kota Jambi. Penelitian berlangsung selama 3 bulan.

Bahan yang digunakan dalam penelitian adalah : benih kakao jenis Upper Amazone Hibrida, zeolit $\left(\mathrm{Na}_{2} \mathrm{AI}_{2} \mathrm{Si}_{3} \mathrm{O}_{10} \cdot 2 \mathrm{H}_{2} \mathrm{O}\right)$, pestisida, pupuk dasar, tanah ultisol, tanah gambut. Sedangkan alat yang digunakan adalah polybag ukuran $5 \mathrm{~kg}$, jangka sorong, timbangan analitik, meteran, oven listrik dan alat-alat tulis.

Penelitian ini dilakukan secara eksperimen menggunakan Rancangan Acak Lengkap (RAL) dengan 2 faktor. Faktor pertama adalah pemberian tanah ultisol (U) dengan 4 taraf yaitu :U0 = tanpa pemberian tanah ultisol, $\mathrm{U} 1=\operatorname{tanah}$ ultisol $15 \%$ berat medium tanam, U2=tanah ultisol $20 \%$ berat medium tanam, U3=tanah ultisol $25 \%$ berat medium tanam. Faktor kedua adalah Zeolit ( $\mathrm{Z}$ ) dengan 3 taraf yaitu : $\mathrm{Z0}=$ tanpa zeolit, Z1 = zeolit 100g, dan Z2 = zeolit 200g. Jumlah kombinasi adalah 12 kombinasi yang diulang sebanyak 3, sehingga diperoleh 36 unit percobaan. Setiap satuan percobaan terdiri dari 3 tanaman, sehingga terdapat 108 bibit kakao.

Areal tempat penelitian dicangkul untuk dibersihkan dari rumput-rumput dan sisa akar tanaman. Kemudian diratakan petak-petak sesuai dengan ukuran petakan percobaan yang telah ditetapkan dan di sekeliling areal diberi pagar untuk menghindari gangguan hewan. Selanjutnya area penelitian dibuat naungan dengan menggunakan atap daun kelapa sawit. Sebelum diberi perlakuan terlebih dahulu dilakukan seleksi benih kakao, memilih benih yang sehat berukuran seragam dari bagian bagian tengah pod atau buah. Media tanam yang digunakan adalah tanah gambut yang diperoleh dari desa Tangkit. Sebelum digunakan terlebih dahulu tanah dibersihkan dari bahan-bahan lain seperti sampah dan batuan. Tanah kemudian dimasukan ke dalam polybag ukuran $5 \mathrm{~kg}$.

Pemberian tanah ultisol dan zeolit dilakukan sebelum tanam, tanah ultisol dan zeolit serta pupuk dasar NPK dicampur merata ke dalam polybag sesuai perlakuan. Pengendalian gulma dilakukan secara manual dengan cara mencabut dan membuang semua gulma yang tumbuh disetiap polybag. Penyiraman bibit dilakukan setiap hari, pada pagi hari, jika turun hujan dan media diperkirakan lembab, penyiraman tidak dilakukan. Untuk mencegah hama dan penyakit dilakukan dengan cara menjaga kebersihan dan memonitoring areal pembibitan secara rutin, bila ada serangan segera dikendalikan secara mekanik bila perlu dilakukan secara kimia. 
Jurnal Media Pertanian Vol. 2 No. 2 Tahun 2017 Hal. 47 - 54

Media Komunikasi Hasil Penelitian dan Review Literatur Bidang Ilmu Agronomi ISSN print $2503-1279$ ISSN online $2581-1606$

Zeolit yang digunakan dalam penelitian ini adalah zeolit powder 60 mesh jenis klinoptilolit dari desa Gedang Sari Gunung Kidul Yogyakarta dengan kandungan $\mathrm{SiO}_{2}$ $78,11 \%, \mathrm{Fe}_{2} \mathrm{O}_{3} 0,69 \%, \mathrm{Al}_{2} \mathrm{O}_{3} 3,94 \%, \mathrm{CaO} 2,10 \%, \mathrm{~K}_{2} \mathrm{O} 0,30 \%, \mathrm{MgO} 0,24 \%, \mathrm{Na}_{2} \mathrm{O}$ $1,54 \%$, DHL $0,06 \mathrm{dS} / \mathrm{m}$, bobot isi $2,2 \mathrm{~g} / \mathrm{cm}^{3}$, volume rongga $35 \%$ dari volume zeolit, kadar air 11,19\%, pH 7,2 dan memiliki Kapasitas Tukar Kation 154,17 cmol(+) $\mathrm{kg}^{-1}$

Pengamatan dilakukan terhadap pertumbuhan bibit kakao terdiri dari : tinggi tanaman $(\mathrm{cm})$, bobot kering tajuk (g), kadar $\mathrm{N}$ daun (\%), dan kadar $\mathrm{P}$ daun (\%). Analisis tanah dilakukan sebelum dan sesudah percobaan terhadap $\mathrm{pH}, \mathrm{N}$ total, KTK dan $\mathrm{P}$ tersedia

Data hasil pengamatan dianalisis menggunakan analisis ragam. Untuk membandingkan rerata setiap variable digunakan uji Duncan New Multiple Range Test (DNMRT) pada taraf $\alpha 5 \%$. Analisa data menggunakan bantuan program Excel Wordsheet dan Statistical Analisis System Versi 17.

\section{HASIL DAN PEMBAHASAN}

Hasil analisis statistik menunjukkan media tanam gambut dan ultisol serta zeolit berpengaruh nyata terhadap semua peubah pertumbuhan tanaman yaitu tinggi tanaman, bobot kering tanaman, kadar $\mathrm{N}$ dan kadar $\mathrm{P}$ daun. Tanaman yang tumbuh pada media tanam gambut yang diberi ultisol $25 \%$ berat medium tanaman plus zeolit 200g (U3Z2) memberikan nilai lebih tinggi dibandingkan dengan perlakuan lainnya.

Hasil analisis statistik perlakuan utama tanah ultisol pada media tanam gambut berpengaruh nyata terhadap tinggi tanaman kakao, bobot kering tajuk, kadar P daun dan kadar $\mathrm{N}$ daun (Tabel 1).

Nilai rata-rata perlakuan ultisol $25 \%$ menghasilkan tinggi tanaman, bobot kering tajuk, kadar $\mathrm{P}$ dan kadar $\mathrm{N}$ daun tertinggi, berbeda nyata dengan perlakuan lainnya. Perlakuan ultisol $25 \%$ dapat meningkatkan tinggi tanaman sebesar 24,24\%, bobot kering tajuk $11,20 \%$, kadar $\mathrm{P}$ daun $25 \%$ dan kadar $\mathrm{N}$ daun $11,74 \%$ jika dibandingkan dengan tanpa pemberian ultisol.

Tabel 1. Pengaruh utama pemberian tanah ultisol pada media tanam gambut terhadap tinggi tanaman (cm), bobot kering tajuk (g), kadar P (\%) dan kadar N (\%) daun.

\begin{tabular}{ccccc}
\hline Ultisol (\%) & $\begin{array}{c}\text { Tinggi } \\
\text { Tanaman } \\
(\mathrm{cm})\end{array}$ & $\begin{array}{c}\text { Bobot Kering } \\
\text { Tajuk }(\mathrm{g}) .\end{array}$ & Kadar P (\%) & Kadar N (\%) \\
\hline 0 (U0) & $26,81 \mathrm{a}$ & $7,41 \mathrm{a}$ & $0,08 \mathrm{a}$ & $2,38 \mathrm{a}$ \\
15 (U1) & $29,62 \mathrm{~b}$ & $7,53 \mathrm{~b}$ & $0,08 \mathrm{a}$ & $2,49 \mathrm{~b}$ \\
20 (U2) & $31,35 \mathrm{c}$ & $7,86 \mathrm{c}$ & $0,09 \mathrm{a}$ & $2,58 \mathrm{c}$ \\
25 (U3) & $33,31 \mathrm{~d}$ & $8,24 \mathrm{~d}$ & $0,10 \mathrm{~b}$ & $2,66 \mathrm{~d}$ \\
\hline
\end{tabular}

Angka yang diikuti oleh huruf kecil yang sama pada setiap kolom adalah berbeda tidak nyata (Uji DMRT $\alpha=0,05)$.

Hasil analisis statistik perlakuan utama pemberian zeolit pada media tanam gambut berpengaruh nyata terhadap tinggi tanaman kakao, bobot kering tajuk, kadar $\mathrm{P}$ daun dan kadar $\mathrm{N}$ daun (Tabel 2). 
Jurnal Media Pertanian Vol. 2 No. 2 Tahun 2017 Hal. 47 - 54

Media Komunikasi Hasil Penelitian dan Review Literatur Bidang Ilmu Agronomi ISSN print $2503-1279$ ISSN online $2581-1606$

Tabel 2. Pengaruh utama pemberian zeolit pada media tanam gambut terhadap tinggi tanaman $(\mathrm{cm})$, bobot kering tajuk (g), kadar P (\%) dan kadar $\mathrm{N}(\%)$ daun.

\begin{tabular}{ccccc}
\hline Zeolit $(\mathrm{g})$ & $\begin{array}{c}\text { Tinggi } \\
\text { Tanaman } \\
(\mathrm{cm})\end{array}$ & $\begin{array}{c}\text { Bobot Kering } \\
\text { Tajuk }(\mathrm{g}) .\end{array}$ & Kadar P (\%) & Kadar N (\%) \\
\hline $0(\mathrm{Z} 0)$ & $24,21 \mathrm{a}$ & $7,05 \mathrm{a}$ & $0,07 \mathrm{a}$ & $2,02 \mathrm{a}$ \\
$100(\mathrm{Z} 1)$ & $32,07 \mathrm{~b}$ & $7,45 \mathrm{~b}$ & $0,09 \mathrm{~b}$ & $2,67 \mathrm{~b}$ \\
$200(\mathrm{Z} 2)$ & $34,53 \mathrm{c}$ & $8,78 \mathrm{c}$ & $0,11 \mathrm{c}$ & $2,91 \mathrm{c}$ \\
\hline
\end{tabular}

Angka yang diikuti oleh huruf kecil yang sama pada setiap kolom adalah berbeda tidak nyata (Uji DMRT $\alpha=0,05$ ).

Nilai rata-rata pemberian zeolit $200 \mathrm{~g}$ menghasilkan tinggi tanaman, bobot kering tajuk, kadar $\mathrm{P}$ dan kadar $\mathrm{N}$ daun tertinggi, berbeda nyata dengan perlakuan lainnya. Perlakuan pemberian zeolit $200 \mathrm{~g}$ dapat meningkatkan tinggi tanaman sebesar $42,62 \%$, bobot kering tajuk 24,54\%, kadar $\mathrm{P}$ daun $57,14 \%$ dan kadar $\mathrm{N}$ daun 44,06\% jika dibandingkan dengan tanpa pemberian zeolit.

Hasil analisis statistik kombinasi perlakuan pemberian tanah ultisol dan zeolit pada media tanam gambut berpengaruh nyata terhadap tinggi tanaman kakao, bobot kering tajuk, kadar P daun dan kadar $\mathrm{N}$ daun (Tabel 3).

Tabel 3. Pengaruh kombinasi pemberian tanah ultisol dan zeolit pada media tanam gambut terhadap tinggi tanaman $(\mathrm{cm})$, bobot kering tajuk $(\mathrm{g})$, kadar $\mathrm{P}(\%)$ dan kadar $\mathrm{N}(\%)$ daun.

\begin{tabular}{cccccc}
\hline $\begin{array}{c}\text { Ultisol } \\
(\%)\end{array}$ & $\begin{array}{c}\text { Zeolit } \\
(\mathrm{g})\end{array}$ & $\begin{array}{c}\text { Tinggi } \\
\text { Tanaman }(\mathrm{cm})\end{array}$ & $\begin{array}{c}\text { Bobot } \\
\text { Kering } \\
\text { Tajuk }(\mathrm{g})\end{array}$ & Kadar P (\%) & $\begin{array}{c}\text { Kadar N } \\
(\%)\end{array}$ \\
\hline $0(\mathrm{U} 0)$ & $0(\mathrm{Z} 0)$ & $22,61 \mathrm{a}$ & $6,88 \mathrm{a}$ & $0,06 \mathrm{a}$ & $1,97 \mathrm{ab}$ \\
& $100(\mathrm{Z} 1)$ & $27,59 \mathrm{c}$ & $7,19 \mathrm{~b}$ & $0,08 \mathrm{bc}$ & $2,48 \mathrm{e}$ \\
& $200(\mathrm{Z} 2)$ & $30,23 \mathrm{~d}$ & $8,14 \mathrm{f}$ & $0,10 \mathrm{~cd}$ & $2,70 \mathrm{gh}$ \\
$15(\mathrm{U} 1)$ & $0(\mathrm{Z})$ & $23,48 \mathrm{ab}$ & $7,06 \mathrm{~b}$ & $0,07 \mathrm{ab}$ & $1,95 \mathrm{a}$ \\
& $100(\mathrm{Z} 1)$ & $30,57 \mathrm{~d}$ & $7,36 \mathrm{c}$ & $0,08 \mathrm{bc}$ & $2,68 \mathrm{~g}$ \\
& $200(\mathrm{Z} 2)$ & $34,81 \mathrm{e}$ & $8,19 \mathrm{f}$ & $0,10 \mathrm{~cd}$ & $2,87 \mathrm{gh}$ \\
& & & & & \\
$20(\mathrm{U} 2)$ & $0(\mathrm{Z} 0)$ & $24,09 \mathrm{~b}$ & $7,11 \mathrm{~b}$ & 16,03 & $2,03 \mathrm{c}$ \\
& $100(\mathrm{Z} 1)$ & $34,16 \mathrm{e}$ & $7,53 \mathrm{~d}$ & $0,09 \mathrm{bc}$ & $2,74 \mathrm{~g}$ \\
& $200(\mathrm{Z} 2)$ & $35,80 \mathrm{ef}$ & $8,94 \mathrm{~g}$ & $0,11 \mathrm{~cd}$ & $2,97 \mathrm{~h}$ \\
& & & & & \\
$25(\mathrm{U} 3)$ & $0(\mathrm{Z} 0)$ & $26,66 \mathrm{c}$ & $7,15 \mathrm{~b}$ & $0,07 \mathrm{ab}$ & $2,12 \mathrm{~d}$ \\
& $100(\mathrm{Z} 1)$ & $35,97 \mathrm{fg}$ & $7,72 \mathrm{e}$ & $0,10 \mathrm{~cd}$ & $2,78 \mathrm{~g}$ \\
& $200(\mathrm{Z} 2)$ & $37,29 \mathrm{gh}$ & $9,85 \mathrm{~h}$ & $0,13 \mathrm{e}$ & $3,09 \mathrm{i}$ \\
\hline
\end{tabular}

Angka yang diikuti oleh huruf kecil yang sama pada setiap kolom adalah berbeda tidak nyata (Uji DMRT $\alpha=0,05)$.

Nilai rata-rata kombinasi pemberian tanah ultisol 25\% (U3) dan zeolit 200g (Z2) pada media tanam gambut menghasilkan tinggi tanaman, bobot kering tajuk, kadar $\mathrm{P}$ dan kadar $\mathrm{N}$ daun tertinggi, berbeda nyata dengan perlakuan lainnya. Perlakuan 
Jurnal Media Pertanian Vol. 2 No. 2 Tahun 2017 Hal. 47 - 54

Media Komunikasi Hasil Penelitian dan Review Literatur Bidang Ilmu Agronomi

ISSN print $2503-1279$

ISSN online $2581-1606$

kombinasi pemberian tanah ultisol 25\% (U3) dan zeolit 200g (Z2) pada media tanam gambut dapat meningkatkan tinggi tanaman sebesar $64,93 \%$, bobot kering tajuk $43,17 \%$, kadar $\mathrm{P}$ daun $116 \%$ dan kadar $\mathrm{N}$ daun meningkat $56,85 \%$ jika dibandingkan dengan tanpa pemberian tanah ultisol dan tanpa zeolit.

Tanah gambut mempunyai $\mathrm{pH}$ berkisar antara 2,8 - 4,5 dan kemasaman potensial mencapai $>5 \mathrm{cmol} / \mathrm{kg}$, ketersediaan unsur-unsur makro $\mathrm{N}, \mathrm{P}, \mathrm{K}$, serta jumlah unsur mikro pada umumnya juga rendah. Tanah gambut mengandung bahan organik yang tinggi tetapi sangat bertolak belakang dengan kandungan unsur hara tanahnya. Hal ini disebabkan proses dekomposisi bahan organik belum sempurna, sehingga status hara tanah gambut sangat miskin. Disamping itu bentuk hara $\mathrm{P}$ pada tanah gambut didominasi bentuk $\mathrm{P}$ organik yang disebut fosfolipida. Fosfolipida tidak dapat dimanfaatkan langsung oleh tanaman, oleh karena itu tanah mineral ultisol dan zeolit sangat berperan untuk mengubah senyawa - senyawa yang tidak tersedia menjadi tersedia bagi tanaman. Ultisol memiliki kandungan bahan organik yang sangat rendah dan apabila tanah ultisol ditambahkan pada tanah gambut maka akan dapat meningkatkan kesuburan tanah, melalui peningkatan perbaikan sifat fisik kimia dan biologi tanah selanjutnya dapat memperbaiki tingkat ketersediaan unsur hara di dalam tanah.

Peningkatan tinggi tanaman, bobot kering tajuk, kadar $\mathrm{P}$ dan kadar $\mathrm{N}$ daun dimungkinkan karena pemberian zeolit pada tanah organik (gambut) dapat meningkatkan $\mathrm{pH}$ dan unsur hara tersedia di dalam tanah. Hasil penelitian Djajadi et al. (2010) mendapatkan bahwa pemberian bahan organik dan zeolit dapat meningkatkan stabilitas agregat dan kapasitas daya pegang air pada tanah pasir. Kemampuan zeolit tersebut dalam meningkatkan stabilitas agregat tanah disebabkan oleh zeolit mengandung unsur-unsur perekat seperti Al dan Si. Menurut Fungaro (2002), struktur zeolit berongga atau memiliki ruang pori sehingga zeolit mampu menyerap sejumlah besar molekul seperti $\mathrm{H}_{2} \mathrm{O}$ yang berukuran lebih kecil atau sesuai dengan rongganya.

Peningkatan $\mathrm{pH}$ oleh zeolit dimungkinkan karena kation-kation basa yang terdapat pada zeolit seperti $\mathrm{Ca} \mathrm{K}$ dan $\mathrm{Mg}$ dapat dipertukarkan dengan ion $\mathrm{H}^{+}$dan $\mathrm{Al}^{3+}$. Zeolit dapat menyangga $\mathrm{pH}$ tanah, tanah masam dapat dinetralisir karena zeolit bersifat tidak masam $(\mathrm{pH} \mathrm{7,2)} \mathrm{dan} \mathrm{dapat} \mathrm{mengadsorpsi} \mathrm{Al} \mathrm{dan} \mathrm{Fe} \mathrm{penyebab} \mathrm{kemasaman} \mathrm{tanah}$ serta melepaskan kation-kation basa seperti Ca, Mg dan K. Endro (2008) menjelaskan bahwa zeolit merupakan mineral yang dapat menetralisir $\mathrm{pH}$ tanah.

Tanaman kakao membutuhkan unsur hara yang diserap melalui tanah. Hara N, $\mathrm{P}$, dan $\mathrm{K}$ diperlukan dalam jumlah lebih banyak. Hara $\mathrm{Ca}, \mathrm{Mg}$, dan $\mathrm{S}$ diperlukan dalam jumlah sedang. Hara $\mathrm{Fe}, \mathrm{Mn}, \mathrm{Zn}, \mathrm{Cu}, \mathrm{B}, \mathrm{Mo}$, dan $\mathrm{Cl}$ diperlukan tanaman dalam jumlah sedikit.. Sebagian besar N dan $\mathrm{P}$ dibawa ke titik tumbuh, batang, daun, dan bunga jantan, lalu dialihkan ke biji. (Olsen dan Sander, 1998).

Kadar $\mathrm{N}$ daun dan kadar $\mathrm{P}$ daun lebih tinggi pada kombinasi pemberian tanah ultisol 25\% (U3) dan zeolit 200g (Z2) pada media tanam gambut jika dibandingkan dengan perlakuan lainnya. Hal ini terkait dengan ketersediaan unsur hara yang ada di dalam tanah. Unsur hara berasal dari dekomposisi dan mineralisasi yang membebaskan unsur-unsur di dalam tanah. Rosmarkan dan Yuwono (2008) menjelaskan bahwa proses mineralisasi tidak lepas dari aktivitas mikrobia tanah sebagai pendekomposisi dan melepaskan unsur hara ke larutan tanah. Peningkatan KTK pada kondisi air tersedia terjadi karena terpicunya mineralisasi dan aktivitas mikrobia tanah peningkat unsur hara tersedia tanah. Mariam dan Hudayana (2002) mendapatkan bahwa peningkatan KTK 
Jurnal Media Pertanian Vol. 2 No. 2 Tahun 2017 Hal. 47 - 54

Media Komunikasi Hasil Penelitian dan Review Literatur Bidang Ilmu Agronomi

ISSN print $2503-1279$

ISSN online $2581-1606$

tanah dapat disebabkan antara lain oleh muatan negatif dari disosiasi gugus fungsional yang dihasilkan oleh mikrobia tanah, semakin banyak muatan negatif maka kation positif makin mudah dipertukarkan. Keizer dan Zech (1996) serta Ansori (2005) menambahkan bahwa meningkatnya KTK berarti bertambah pula muatan negatif tanah sehingga dengan demikian akan terjadi penolakan anion, hal ini berakibat pada peningkatan konsentrasi $\mathrm{P}$ dalam larutan tanah.

\section{KESIMPULAN}

1. Pemberian tanah ultisol dan zeolit pada media gambut dapat mempengaruhi pertumbuhan tanaman kakao secara signifikan terutama pada tinggi tanaman, bobot kering tajuk, kadar $\mathrm{N}$ daun dan kadar $\mathrm{P}$ daun.

2. Tanah ultisol $25 \%$ dan zeolit $200 \mathrm{~g}$ pada media gambut dapat lebih baik mempengaruhi pertumbuhan bibit kakao

\section{DAFTAR PUSTAKA}

Agus. F dan Subiksa. I.G.M. 2008. Lahan Gambut Potensi Pertanian dan Aspek Lingkungan. Balai Penelitian Tanah. Badan Penelitian dan Pengembangan Pertanian. Bogor.

Al-Jabri, M. 2008. Tantangan dan Peluang Pengembangan Pembenah Tanah Zeolit Pada Lahan Terdegradasi Untuk Peningkatan Produksi Tanaman Pangan. http://balittanah.litbang.pertanian.go.id/ind/dokumentasi/prosiding2008pdf/aljabri zeolit.pdf.

Ansori. L. 2005. Serapan unsur P, hasil dan kualitas Jagung Manis (Zea mays saccharata Sturt) pada tanah ultisol yang diberi kotoran ayam dan pupuk fosfat (tesis).Palembang. Pascasarjana Unsri.

Balai Benih Induk (BBI) Hortikultura. 2002. Provinsi Jambi.

BB litbang SDLP (Balai Besar Penelitian dan Pengembangan Sumberdaya Lahan Pertanian). 2011. Laporan Tahunan 2011, Konsorsium Penelitian Dan Pengembangan Perubahan Iklim Pada Sektor Pertanian. Balai Besar Penelitian Dan Pengembangan Sumberdaya Lahan Pertanian, Bogor.

Dinas Perkebunan. 2008. Propinsi Jambi. hhtp//Produtivitas Kakao Dipropinsi Jambi.05 Nopember 2014.

Direktorat Jenderal Perkebunan, Departemen Pertanian.2008. Pedoman Umum Penyediaan BibitKakao. Jakarta.

Harjadi, S.S. 2002. Pengantar Agronomi. PT GramediaPustaka Utama. Jakarta.

Hardjowigeno, S. 2003. Ilmu Tanah. Akademika Pressindo. Jakarta

Hikmah, N. 2006. Peranan Zeolit Dalam Pelepasan Nitrogen Dari Pupuk Tersedia Lambat (slow Release Fertilizers). Departemen Ilmu Tanah dan Sumberdaya Lahan Fakultas Pertanian Institut Peertanian Bogor. Bogor

Lingga, P. 1995. Petunjuk Penggunaan Pupuk. Penebar Swadaya. Jakarta.

Mariam. S dan Hudaya. R. 2002. Pengaruh pupuk organik dan SP 36 terhadap beberapa sifat kimia andisol serapan $\mathrm{P}$ dan hasil tanaman kubis (Braaica oleiaccea) . Soil Lens . 3(6): 275-282.

Prawoto. A, Santoso. B, Wibawa.A, Sulistywati.E, Winarno. H, 2004. Pusat Penelitian Kopi dan Kakao Indonesia. Panduan Lengkap Budidaya Kakao. Agromedia.Depok. 
Jurnal Media Pertanian Vol. 2 No. 2 Tahun 2017 Hal. 47 - 54

Media Komunikasi Hasil Penelitian dan Review Literatur Bidang Ilmu Agronomi ISSN print $2503-1279$ ISSN online $2581-1606$

Rahmawati. 2006. Pengaruh pemberian Zeolit dan Kompos TKS Terhadap Beberapa Sifat Fisik dan Serapan P Tanaman Jagung (Zea mays L.) Pada Tanah Typic Paleudult. Universitas Sumatera Utara. Medan.

Suwardi. 1997. Studies on agricultural utiliz ation of natural Zeolites in Indonesia.

$\mathrm{Ph}$. D. Dissertation. Tokyo University of Agriculture.

Sibagaring. DA, dan Yetti. H. 2013. Pengaruh Pemberian Tanah Mineral dan Aerasi

Pada Tanah Gambut Yang Disawahkan Terhadap Pertumbuhan dan Produksi

Tanaman Padi (Oryza sativa. L) download.portalgaruda.org/article.php. Diakses 3 September 2016.

Siregar, T, H. Slamet, R. Liali, N. 2014. Budidaya Cokelat. Penebar Swadaya. Jakarta.

Soil Survey Staff. 2003. Key to Soil taxonomy. ${ }^{\text {th }}$ Edition. United States Department of Agriculture. Natural Resources Conservation Service.

Suhardi. A. 2010. Dasar-dasar Bercocok Tanam.Kanisus.Yogyakarta.

Sutedjo. H. 2010. Pedoman Bercocok Tanam Cokelat. Penebar Swadaya. Jakarta

Suwarto dan Yuke. 2010. 12 Budidaya Tanaman Perkebunan Unggulan. Penebar Swadaya. Jakarta. 